\title{
Gerencia en la integración latinoamericana: Una comparación entre el Pacto Andino y MERCOSUR.
}

\author{
Isaías Lescher Soto (*)
}

\section{Resumen}

Tomando en consideración que la Gerencia de la Integración Latinoamericana ha estado relacionada con la implantación de Estrategias de Desarrollo, que han condicionado el perfil de los acuerdos en cuanto a la formulación de objetivos y políticas y la burocracia del proceso, el presente Artículo analiza comparativamente como la sustitución de importaciones modeló una integración proteccionista basada en la industrialización y con alto nivel de desarrollo burocrático, mientras la estrategia aperturista ha provocado una integración abierta al mundo, basada en el libre mercado y con un austero perfil institucional.

Palabras claves: Integración Latinoamericana, Pacto Andino, Mercosur, Desarrollo, Burocracia.

\section{Latinoamerican integration management: a comparative point of view between the Pacto Andino and MERCOSUR}

\section{Abstract}

Taking into consideration that the Latinoamerican Integration Management has been related wilth the implementing Development strategies, that have conditioned the characteristics in the formulation of objectives and politics and the bureaucracy process agreements, the porpuse of this paper is to show in a comparative manner as the

Fecibido: 25-10-96 - Aceptado: 19-12-96

* Sociólogo, Profesor de la Escuela de Sociología de LUZ en las áreas de Análisis Social de Venezuela e Integración Latinoamericana. Dirección Calle 60B \#9B-73. Maracaibo-Venezuela. 
substitution of imports modeled an integration protectionist based on the industrializantion and a very high level of bureaucratic developmnet, while the opening model has origenated a wide open integration to the world, based on the free market an a low institutional profile.

Key words: Latinoamerican Integration, Pacto Andino, Mercosur, Development, Bureaucracy.

\section{Introducción}

La integración Latinoamericana no constituye un proyecto novedoso; durante las décadas de los años 50 y 60 , se establecieron propuestas importantes sobre procesos de liberación comercial y uniones aduaneras, tal es el caso del Mercado Común Centroamericano (1960) y el Acuerdo de Cartagena o Pacto Andino (1969). En el marco de la estrategia de desarrollo basada en la sustitución de importaciones, estos esquemas integracionistas propiciaban la creación del libre comercio entre los países signatarios de los Acuerdos y al mismo tiempo garantizaban una relativamente alta protección frente a terceros.

Sin embargo, a comienzos de la década de los años 80 , los logros de muchos de los Proyectos eran discutibles. El estancamiento de los procesos de integración luvo que ver con la crisis de la estrategia de desarrollo, con la falta de voluntad política para cumplir con los objetivos de los Acuerdos, así como factores como la heterogeneidad de los países, la escasa interdependencia económica y política; y la vulnerabilidad de las economías en relación a los acontecimientos de la economia mundial (Morón, 1994: 102).

La crisis de la deuda marcó el abandono de la estrategia "Desarrollista" y significo la parálisis completa de la integración durante los años 80 ; la insolven- cia de la mayor parte de los países de la región, condicionó el otorgamiento de nuevos créditos a severos programas de ajuste macroeconómico prescritos por los Organismos Financieros Multilaterales (FMI-BM). De esta forma, el modelo proteccionista cedió ante un esquema neoliberal que auspiciaba la apertura unilateral de las economías de la región al exterior.

En respuesta a la prolongada crisis, América Latina ha observado una capacidad reactiva en los gobiernos y sociedades civiles en la búsqueda de nuevos mecanismos para gerenciar los nuevos desafíos de la región. En este contexto se ha producido un renovado interés por la integración. Esto se explica, por condiciones internacionales como el perfeccionamiento de la comunidad europea, la concertación de una zona de libre comercio en América del Norte y el futuro progreso de las negociaciones en la Organización Mundial del Comercio, sucesora del Acuerdo General de Aranceles Aduaneros y Comercio (GATT). A nivel interno actúan como factores propiciadores de la integración, la convergencia de modelos económicos, la creciente afinidad política entre gobiernos democráticos y la creciente liberalización comercial.

La incorporación del interés integracionista en la agenda de los gobiernos latinoamericanos ha propiciado la suscripción de importantes acuerdos bilate- 
rales y multilaterales. Entre estos, el Mercado Común del Sur (MERCOSUR), donde se reúnen Argentina, Brasil, Paraguay y Uruguay puede caracterizarse como parte de los nuevos esquemas de integración regional latinoamericanos de los años 90 .

Este trabajo tiene como fin establecer semejanzas y diferencias de la Gerencia de la integración en América Latina, especificamente ol Pacto Andino y MERCOSUR, por representar estos "lo viejo" y "lo nuevo" de los paradigmas integracionistas tomando en cuenta su relación con las estrategias de desarrollo, su burocracia, los instrumentos de política que han seguido y finalmente algunos de los logros obtenidos en el presente, entre esos su posición actual en el "ranking" integracionista del comercio internacional, el establecimiento de uniones aduaneras y sus relaciones con otros bloques.

\section{Estrategias de desarrollo y gerencia integracionista}

La primera consideración importante que hace diferentes los dos acuerdos de integración antes mencionados es el contexto en el cual se originan, configuran y consolidan.

Este contexto en América Latina ha estado relacionado con la implantación de estrategias de desarrollo o proyectos políticos por parte de los gobiernos de turno, a partir de los cuales se definen las políticas públicas que dan orientación a las funciones del Estado y al estilo de desarrollo económico, social y cultural en cada país de la región. La integración, como se verá, forma parte de las estrategias de desarrollo.

En este sentido, es necesario retomar el hecho de que mientras el Pacto Andino surge en momentos cuando el modelo de sustitución de importaciones en la subregión estaba siendo implantado como estrategia de desarrollo; el MERCOSUR surge en medio de la apertura unilateral iniciada en América Latina a partir de los condicionamientos de los Organismos Financieros Multilaterales.

En el primer caso, la estrategia basada en la industrialización substitutiva tuvo su inicio en algunos países de Latinoamérica de manera espontánea durante la gran crisis de los años treinta, cuando se evidenció la incapacidad del mercado para superar en forma rápida los desequilibrios económicos cíclicos. Este cuestionamiento dio lugar a la concepción de que el Estado, debía desempeñar un papel activo para superar este tipo de problemas.

De esta manera, el que se haya optado por una estrategia de industrialización "hacia adentro" y no "hacia a fuera", más que obedecer a alguna posición teórica sobre el Desarrollo, parece haber sido fruto de un accidente histórico. En efecto la crisis de los años treinta y el deterioro de los términos de intercambio, así como la segunda Guerra Mundial y el proteccionismo que prevaleció en los países industrializados, hizo más difícil para la región importar productos manufacturados y más atractiva la producción interna. Cabe señalar, además que el argumento teórico de la CEPAL, desarrollado por Prebish fue formulado muchos años 
después de que esa política se pusiera en marcha (Ramos, 1993: 66).

La política para fomentar la industrialización tuvo entre sus características más importantes:

1. Protección arancelaria mayor para los productos finales que para los insumos intermedios y menor para los bienes de capital.

2. Protección paraarancelaria como cuotas y licencias de importación, prohibiciones totales, exigencias de mayor contenido nacional en el valor agregado de la producción, créditos preferenciales.

3. Alto nivel de intervención gubernamental tanto en la política comercial como macroeconómica.

Sólo es a fines de la década de 1950 e inicios de la de 1960, cuando la CEPAL, propuso una formulación para orientar el desarrollo de la región. Entre las medidas de políticas económicas se propuso la integración con la cual se pretendia asemejar "las estructuras productivas de la periferia" a las del "centro" superando los "cuellos de botella" de la industrialización (Rodríguez, 1992: 6-7).

La propuesta tuvo primera y segunda respuesta en la conformación del Mercado Común Centroamericano y la Asociación Latinoamericana de Libre Comercio (ALALC). La tercera respuesta fue la creación del Pacto Andino, el cual buscó coordinar el desarrollo de la ALALC e intentaba avanzar hacia un mercado común. Es necesario mencionar que el pacto buscaba incrementar el poder de negociación de los países de la subregión (Colombia, Bolivia, Ecuador, Chile y Perú) frente a las mayores economías latinoamericanas como la de
Brasil, Argentina y México, participantes en la Asociación.

El acuerdo Cartagena, protocolo del Pacto Andino, se configuró en función de los elementos fundamentales de la intervención estatal y con un esquema de marcado proteccionismo, especialmente para el sector industrial, a nivel de la subregión. En este sentido, tuvo gran relevancia la programación industrial, la cual tenía como fin brindar impulso a aquellos sectores considerados modernos, relacionados con el capitalismo industrial. Además de estos se privilegió el capital nacional y subregional, estableciendo restricciones a la inversión extranjera; en efecto, con la Decisión 24 se buscaba promover la nacionalización de los capitales extranjeros dentro de la subregión andina. Esto a corto plazo provocó la salida de Chile en 1976, como producto de las diferencias de este país en lo referente al trato dado por el gobiemo militar de derecha de Augusto Pinochet al capital internacional. El control del ingreso de inversiones extranjeras conlievó en gran medida a beneficiar la creación de monopolios y oligopolios y no dio grandes resultados en cuanto a la promoción del desarrollo interno dentro del área Andina.

Se argumentaba que la integración económica era necesaria dentro de la estrategia de industrialización substitutiva puesto que constituía un medio para mantener una tasa satisfactoria de crecimiento general, promoviendo el desarrollo de industrias eficientes que podrían competir a mediano y largo plazo en los grandes centros industriales.

La integración podía coadyuvar a superar las restricciones que le imponia 
una balanza de pagos en donde se evidenciaba un lento aumento de las exportaciones de bienes y servicios en comparación con una elevada tasa de crecimiento de las importaciones. En este sentido la fuente principal de desarrollo dentro de un mercado ampliado de varios países sería precisamente la expansión de las exportaciones industriales entre sus miembros.

Al respecto cada país podría especializarse en la o las industrias substitutivas que considerara más convenientes según los recursos con los cuales cuente.

Una de las virtudes de la integración según lo antes visualizado sería la expansión constante y sistemática de los mercados como producto de la liberación del comercio entre el grupo de países firmantes de los acuerdos.Según datos de la Junta del Acuerdo de Cartagena (JUNAC) entre principios de la década de los años 60 y principios de la década de los años 80 , el comercio intrasubregional de manufacturas alcanzó un crecimiento promedio de $39 \%$ anual, asimismo el mercado subregional creció entre fines de los años 60 y principios de los años 80 en un promedio de $25 \%$, mientras las exportaciones andinas al resto del mundo crecieron en un 35\% (CINDA, IALALC, 1987: 133-134). Más adelante se observará que la crisis de los 80 paralizó los logros iniciales del acuerdo.

Al final del periodo estudiado, los productos más importantes en el comercio interegional fueron para Perú, las exportaciones de cobre, fibras artificiales $y$ derivados del petróleo; Ecuador exportó petróleo, derivados del petróleo, pescado preparado; crustáceos y moluscos; Vene- zuela (miembro del acuerdo desde 1973) exportó derivados del petróleo, productos quimicos, productos de acero y aluminio, mientras Colombia contribuyó con carne, algodón, productos químicos y manufacturas livianas como ropa y artículos para viajes. Finalmente Bolivia participó con azúcar, madera, químicos y metales no ferrosos (Baumann, 1993: 137).

Durante este período los países que hoy conforman el MERCOSUR, no habian tenido una posición relevante en cuanto a acuerdos integracionistas. Tratándose el caso de Brasil, por ejemplo, los gobiernos militares posteriores a 1964 , específicamente los de los Generales Castillo Branco y Costa Silva, buscaron un acercamiento mayor con los Estados Unidos, lo cual implicó una desvalorización relativa del escenario regional, al tiempo que buscó definirse una estrategia de seguridad nacional que implicaba apoyo a regímenes militares como el de Bolivia y desconfianza hacia gobiernos democráticos civiles como el de Chile en los 60. A diferencia de los demás Estados de la región, Brasil, pudo continuar la política de industrialización substitutiva de impor* taciones, complementada con una vigorosa política exportadora, no siendo esta última dirigida al mercado regional fundamentalmente, sino que ha procurado abrir mercados en todo el mundo.

Por otro lado, Argentina, el otro mercado relevante del MERCOSUR, en el período estudiado, tampoco mostró una política integracionista importante, basándose sus relaciones con el exterior en negociaciones bilaterales más diplomáticas que comerciales con Brasil y Chile (CINDA, IALALC, 1987: 283-298). 
Sin embargo, a mediados de los años 80 el cambio a gobiernos civiles en ambos paises, luego de un largo periodo de regimenes militares, propició un nuevo esquema de integración.

Los gobiernos de Raúl Alfonsin en Argentina y Sarney en Brasil implementaron casi simultáneamente programas de ajuste económico a la luz de la crisis de la deuda para combatir la inflación y el déficit fiscal. Argentina además inició un proceso de apertura unilateral hacia las importaciones con to cual el comercio entre ambos palses se incrementó.

Estas condiciones, permitieron a corto plazo la negociación de un Programa de Integración y Cooperación Económica (PICE) el cual fue firmado en 1986 y estaba contormado por doce protocolos de cooperación en áreas productivas, financieras, culturales, tecnológicas $y$ cientificas.

El 29 de noviembre de 1988 se firmó el Tratado de Integración, Cooperación y Desarrollo entre Argentina y Brasil, el cual entró en vigencia en agosto de 1989. Estableció una primera etapa de reducción gradual de los obstáculos tarifarios y no tarifarios al comercio de bienes y servicios, la armonización de algunas políticas (aduaneras, comercial, ciencia y tecnologia) y la coordinación de políticas macroeconómicas (fiscal, monetaria y de capitales).

A partir del Acta de Buenos Aires (Junio de 1990) se modifica la estrategia de integración, cuando los Presidentes Menem y Collor decidieron acelerar el proceso para conformar un mercado común el 31 de diciembre de 1994 sobre la base de rebajas generalizadas y automá- ticas de todo el universo arancelario y la desaparición de barreras paraarancelarias. En este sentido el mecanismo integracionista fue fundamentalmente el desmantelamiento de barreras comerciales.

Finalmente, el 29 de mayo de 1991, se firmó el tratado de Asunción, que extiende las metas del Acta de Buenos Aires a Paraguay y Uruguay creándose el Mercado Común del Sur (MERCOSUR).

Este nuevo acuerdo, a diferencia del Grupo Andino, surge en momentos en que una nueva estrategia de desarrollo se implanta en América Latina, así como también se hace más larga la lista de países de la región en democracia.

Así como la gran crisis de los años treinta dio paso a una desconfianza creciente a las ventajas de los mecanismos de libre mercado y llevó, por ende, a que el Estado iniciara una práctica activa de industrialización, la crisis de los 80 mostró las limitaciones tanto de la sobre-extensión del Estado como de una estrategia de desarrollo orientada hacia adentro. Esto dio origen a un cambio que condujo las modalidades de acción de los gobiernos a una orientación hacia afuera, a un mayor uso de los mecanismos de mercado y a una redefinición de los roles de los sectores privado y público, en el que el primero debía tener la conducción, mientras el segundo centraría sus funciones en corregir las fallas que podria producir el libre juego de la oferta y la demanda.

Los medios utilizados fueron la reducción de los aranceles; según la CEPAL, a nivel de la región pasaron de $45 \%$ a menos de $20 \%$ de arancel nominal medio. Además, el nuevo entoque vino acompañado de instrumentos de política como la 
reducción del gasto público, la liberación del tipo de cambio, de las tasas de interés, la desregulación de los mercados de trabajo, entre otras (Ramos, 1993: 74).

En este marco, la integración presenta características diferentes. Los bajos aranceles constituyen el elemento principal, perdiendo importancia la programación sectorial o industrial.

La integración se hace de esta manera "superficial", es decir con un alcance básicamente comercial.

Otra de las características que hacen diferente la integración de hoy a partir de la nueva estrategia de desarrollo es lo referente a la protección; los acuerdos (como producto de la apertura unilateral de las económicas) no tienen como fin crear espacios ampliados protegidos para la producción industrial, sino mecanismos para vincularse con mayor competitividad a la economia internacional.

En los países del MERCOSUR la búsqueda de la internacionalización de las economías es evidente; en Argentina por ejemplo el arancel máximo entre 1986 y 1992 se redujo de 65 a $30 \%$ y mientras que en Brasil éste lo hizo de 105 a 35\%.

Los resultados iniciales del MERCOSUR son elocuentes en 1985 el comercio entre Argentina, Brasil, Paraguay y Uruguay representaba $28 \%$ de los intercambios al interior de la Asociación Latinoamericana de Integración (ALADI) sucesora de la ALALC, mientras en 1994 esta cifra superó el 43\% (FERRER, 1995: 821).

El perfil exportador del MERCOSUR se caracteriza de la siguiente manera: Argentina exporta primordialmente trigo, productos lácteos, frutas, nueces, y derivados del Petróleo, productos de acero y repuestos de automóviles; Uruguay aporta, carne, arroz, preparados de cereales $y$ algunos productos químicos como pigmentos y pintura; mientras que Paraguay exporta algodón, carne, café y aceites esenciales. Brasil finalmente, comercializaba café, minerales y concentrados de hierro, derivados del petróleo, productos de acero y automóviles (Baumann, 1993: 136). Sin embargo existen datos que reflejan que entre los mayores socios (Argentina y Brasil), el $53 \%$ del comercio bilateral ha estado constituido en los últimos años por manufacturas (Morón 1994: 108).

Paralelamente, al desarrollo de MERCOSUR, los países del Pacto Andino tambiên habian realizado un proceso de apertura económica desde mediados del decenio de los 80 , inicialmente Bolivia y posteriormente Venezuela y Colombia al igual que Perú. Un ejemplo de la transformación sufrida por los países miembros de este acuerdo se visualiza con la disminución de los aranceles, los cuales se ubicaban en la subregión en un máximo que variaba entre 80 y $300 \%$, mientras que posteriormente a la apertura, los aranceles andinos fluctúan entre un $5 \%$ y un $35 \%$ (Thoumi, 1993: 76).

Al mismo tiempo en una reunión durante el mes de marzo de 1991 en Cartagena (Colombia) se estableció el acuerdo conocido como el Acta de Barahona a través del cual se propone establecer una unión aduanera a partir de 1992. Sin embargo, la parálisis de los acuerdos de integración iniciales provocada por la crisis económica por la cual atraviesan los países de la región se observaba en la poca relevan- 
cia que para este período tenía el comercio global entre los paises signatarios, mientras que más de un tercio del mismo correspondía a la relación Colombia-Venezuela, según indicaba la CEPAL(Rojas, 1993: 62). Asimismo se presentaban graves factores políticos como el autogoipe de Alberto Fujimori en Perú durante el mes de abril de 1992, los intentos de golpe de Estado en Venezuela y el recrudecimiento de las guerras civiles en Colombia. Todo este contexto llevó a la separación temporal de Perú del tratado y el fracaso en las negociaciones sobre el Arancel Externo Común.

Frente a esto la principal opción surgida ha sido el acuerdo Colombo-Venezolano de libre comercio.

En síntesis, en cuanto a la relación entre estrategias de desarrollo e integración, lo más relevante ha sido diferenciar que la primera ha condicionado el estilo que han asumido los tratados integracionistas, propiciando asimismo la posición entre los países signatarios y su relación conjunta con el resto del mundo. De esta manera la estrategia desarrollista de sustitución de importaciones condicionó el perfil del crecimiento "hacia adentro" del Pacto Andino y su mecanismo de programación industrial y sectorial, a diferencia del MERCOSUR que se originó en momentos que la estrategia de desarrollo neoliberal exigia una apertura indiscriminada hacia la economía mundial.

\section{La burocracia de la Integración}

La integración es un área de política pública que desarrolla metas, contenidos y gestión especificas, con importan- tes niveles de especialización en sus procesos decisorios. Asimismo la integración se perfila como un ejercicio de voluntad politica entre diferentes soberanias (Escobar, 1993: pp 62-63).

La configuración del proceso integracionista, como proceso gerencial, se planifica, organiza, dirige y controla en un espacio internacional que incluye a los Estados-Gobiernos de los países signatarios pero que se operacionaliza a nivel de las organizaciones que ejecutan los grandes protocolos firmados por los representantes gubernamentales. De esta manera, uno de los factores divergentes entre la vieja y la nueva integración de América Latina es lo referente a los organismos supranacionales 0 instituciones comunes. La Burocracia de los antiguos programas de integración contrasta con los mecanismos de concertación política de la actualidad, basados fundamentalmente en relaciones intergubernamentales y entre el sector privado de los países signatarios.

En la integración de los años 90; los objetivos y metas son más puntuales: lograr el libre intercambio de bienes, servicios y factores entre las naciones suscriptoras de los pactos; por lo cual las instituciones creadas desarrollarán acciones enmarcadas dentro de estos fines. En los anteriores modelos, integracionistas las metas se conectaban con objetivos de desarrollo mucho más complejos por lo cual las instituciones creadas tenian misiones sociales, culturales financieras entre otras de carácter diplomático o político.

En efecto el Acuerdo de Cartagena dio origen a algunas Instituciones de pertil 
político, técnico, burocrático, entre las cuales se pueden identificar (CINDA, IALALC, 1987: 145-164):

1. La Comisión del Acuerdo de Cartagena: Que constituye el máximo organismo del acuerdo, de carácter intergubernamental, el cual aprueba, rechaza o enmienda los programas y proyectos del Pacto Andino.

2. La Junta del Acuerdo: Organismo técnico del acuerdo, su función se centra en velar por la implantación del acuerdo, evaluando el proceso en cumplimiento de las decisiones de la comisión. Esta junta a su vez ha creado como mecanismo de armonización de políticas diversos consejos, entre los que se cuentan: El de planificación monetaria y cambiaría, el de financiamiento, el de política fiscal, el de comercio exterior, el de turismo, el de asuntos sociales, el de salud, el de integración física, el agropecuario y el de estadística.

3. Comité Consultivo: En este organismo, los gobiernos signatarios del acuerdo analizan y evalúan las proposiciones de la Junta.

4. Comité Asesor Económico (CAES), es un organismo representante de los trabajadores y empresarios de los paises miembros.

5. Tribunal de Justicia: Cuyo fin es resguardar el cumplimiento de las normas que conforman el ordenamiento jurídico del Acuerdo de Cartagena.

6. Reuniones de jefes de Estado: Constituyen la cúpula del Sistema Institucional para la cooperación política de integración económica.
7. El Consejo Andino: Donde participan los Ministros de Relaciones Exteriores, con la finalidad de coordinar las políticas exteriores de los países miembros asi como formular una política internacional conjunta andina.

8. El Parlamento Andino: Se le asigna la función de sustentar y fortalecer los sistemas democráticos, preservar los derechos humanos y propiciar la participación de un mayor número de actores políticos en las actividades relacionadas con la integración.

9. Corporación Andina de Fomento: Institución encargada de financiar proyectos de producción de bienes y servicios, asl como apoyar los ya existentes.

10. Convenio "Andrés Bello", fue suscrito en 1970 por los Ministros de Educación de los países miembros, con el fin de generar el desarrollo en áreas de educación, ciencia y cultura.

11. Convenio "Simón Rodríguez": Su creación se dio por la firma de los Ministros de Trabajo de los participantes en el Acuerdo de Cartagena en 1973, tiene como propósito diseñar estrategias que conduzcan al mejoramiento de las condiciones de vida y de trabajo, asimismo el tratamiento de los problemas sociolaborales en la subregión Andina.

12. Convenio "Hipolito Uname": Acuerdo firmado por los Ministros de Salud en 1971, con el objetivo de crear estrategias para solucionar y prevenir los problemas relacionados con enfer- 
medades transmisibles, las migraciones poblacionales, el saneamiento ambiental, desnutrición, drogas, productos biológicos y problemas de salud fronterizos.

13. Convenio "Celestino Mutis": Creado en 1983, postula la adopción de mecanismos para perfeccionar los sistemas nacionales de seguridad alimentaria.

Como puede observarse los fines y medios de la integración Andina descansan en una compleja red de organismos que en gran medida han sufrido también los efectos de la crisis, to cual se evidencia con el clerre temporal que debió enfrentar la Junta del Acuerdo de Cartagena durante los Primeros meses de 1996, como producto del retraso en la cancelación de las cuotas para el mantenimiento de la institución por parte de Perú y Bolivia.

A diferencia del Pacto Andino, el MERCOSUR ha creado una serie de organismos transitorios (Castro, 1994: 992) que se establecieron inmediatamente después de la firma del tratado de Asunción:

1. El consejo del Mercado Común: Integrado por los Ministros de Relaciones Exteriores y Economía de los cuatro países, a cargo de la Dirección de Coordinación Política del Proceso.

2. El Grupo del Mercado Común: Se constituyó en un foro ejecutivo de los Ministros de Relaciones Exteriores.

3. La Secretaria Administrativa: Con sede en Montevideo (Uruguay).

4. Las Comisiones Técnicas, que son 14 y los Sub-Grupos de trabajo entre los que destacan: Asuntos Comer- ciales, Asuntos Aduaneros, Normas Técnicas, Políticas Fiscal y Monetaria Relacionadas con el Comercio, Transporte Terrestre, Transporte Marítimo, Política Industrial y Tecnológica, Política Agrícola, Politica Energética y Coordinación de Políticas Macroeconómicas.

No es objetivo de este artículo, senalar las ventajas o desventajas de los dos estilos, pero es necesario aclarar algunos aspectos.

La divergencia en la creación y enfoque dado a las instituciones tiene que ver, como se ha planteado, con los objetivos que se le han asignado a los procesos integracionistas en los dos casos mencionados; en el primero de ellos el Acuerdo Andino establecía como objetivo promover el desarrollo equilibrado y armónico de los paises miembros, acelerar el crecimiento y facilitar la participación de estos en la ALALC. Mientras el MERCOSUR ha señalado objetivos más "comerciales" como: La libre circulación de bienes, servicios y factores productivos entre los miembros; el establecimiento de un Arancel Externo Común y la adopción de una política comercial frente a terceros, coordinar políticas macroeconómicas y armonizar la legislación en las áreas correspondientes.

Debido a lo anterior, las instituciones en el primer caso, es decir en el Grupo Andino tendrán como tín coadyuvar con el desarrollo integral de los países signatarios, además de canalizar los aspectos relacionados con la prácticas de integración. La complejidad de la misión de estos organismos los hace dependientes no solo de la existencia de recursos 
para su mantenimiento, sino además requieren del apoyo político de los gobiernos así como también el desarrollo continuo del personal adscrito a estas instituciones. Por tales razones han sufrido el deterioro o estancamiento propio de la mayoría de los entes administrativos pertenecientes al sector público Latinoamericano.

En efecto, los problemas que agobian actualmente al Estado Latinoamericano en cuanto a la obsolescencia tecnoburocrática de sus organismos, la baja calidad en los procesos, necesidad de mejoramiento y actualización del Recurso Humano se han extendido a este tipo de Instituciones provocando problemas de eficacia y eficiencia que se han traducido en un bajo perfil en cuanto a logros observables.

Como se verá, los avances del Pacto Andino pueden calificarse como mayormente "Comerciales", mientras las grandes metas sociales, politicas y culturales no aparecen como fortalezas de este acuerdo sino más bien como desaflos hacia el próximo siglo.

Lo anterior, tiene evidente relación con la falta de voluntad política para dar viabilidad a los proyectos integracionistas y a la poca correspondencia entre estos y las decisiones de políticas públicas al interior de los países miembros.

En el MERCOSUR los organismos desarrollan actividades relacionadas con el control del cumplimiento de los procedimientos del proceso integracionista, así como la resolución de problemas generados por la integración. El peso del logro de las metas, por tratarse de un acuerdo enmarcado dentro de la estrategia de desarrollo neoliberal, queda en manos del mercado, es decir es el libre juego de la oferta y la demanda, entendiéndose esto en la posición que asuma el sector privado y los consumidores. El sector público y en este caso las instituciones creadas por la integración, tendrán la misión de corregir las distorsiones provocadas por las liberalización del comercio propiciando la negociación entre las partes que entren en conflicto, y de la misma manera establecen o coordinan la normalización necesaria para prevenir y solucionar controversias.

Esta focalización de la acción de los Organismos encargados de gerenciar la integración ha llevado en parte y con la ayuda de voluntad política, como se verá posteriormente, a que las metas globales del Acuerdo suscrito por los países miembros, se hayan cumplido con una relativa mayor facilidad que en el caso anterior.

Sin embargo, este enfoque integracionista no ha considerado las variables sociales y culturales relacionadas con la integración, no solo desde el punto de vista de los efectos reales que esta pueda tener a mediano y largo plazo en las "sociedades integradas", sino la importancia que dichas variables pueden tener al momento de formular las estrategias que conlleven al cumplimiento de las metas establecidas, a nivel comercial.

\section{Lineamientos de acción de la gerencia integracionista}

Las características de la estrategia de desarrollo, así como los objetivos asignados a la integración, determinaron también los fundamentos que hacen viables 
las líneas de acción que concretan los acuerdos.

De esta manera se observa que durante su inicio y consolidación el Pacto Andino ha establecido algunos mecanismos para lograr los objetivos, entre los que se tienen: Programas de armonización de políticas económicas y sociales entre los paises miembros, programación industrial conjunta, la cual contemplaba el área metalmecánica, petroquímica y automotriz.

Asimismo dentro del acuerdo de Cartagena se establecían programas de racionalización de industrias ya existentes, Proyectos de Desarrollo Agropecuario, Proyectos Multilaterales de Integración Fisica, Programas Andinos de Desarrollo Tecnológico, entre otros.

Además, dentro del acuerdo de Cartagena se consideró un programa de liberación del intercambio que comprendía el Universo Arancelario, eliminando los aranceles de manera absoluta el 31 de diciembre de 1980 .

Como se sabe, poco se ha cumplido de todos estos programas y se señala que a partir de 1983, el comercio subregional se limitó por toda clase de restricciones como prohibiciones, licencias previas, reservas de importación al Estado, depósitos previos y requerimientos obligatorios de financiamiento adicional. Se señala que en 1985 había disminuido en un $50 \%$ el comercio reciproco merced a esta red de obstáculos de toda índole. Así por ejemplo, Venezuela durante un largo período detuvo las importaciones de sus socios Andinos (CINDA, IALALC, 1987: 134).
Sin embargo, a través de las reuniones de Galápagos (1989) y Cartagena (1991), se ha tratado de perfeccionar la zona de libre comercio, de la cual se ha retirado Perú, y adoptar un Arancel Externo común; se ha negociado eliminar totalmente las listas de excepciones y la nómina de productos reservados a la programación industrial, con lo cual se ha procurado que todo el Universo Arancelario quede sujeto a liberación. Se dio término al mecanismo de programación industrial, derogándose el programa automotor. Se ha reformado el régimen para el capital extranjero.

En general se ha tratado de modificar el perfil de los instrumentos de politica que habian caracterizado el acuerdo durante los primeros años de funcionamiento.

En cuanto al MERCOSUR, los mecanismos consisten primeramente en la liberación comercial, cuyo cronograma se fijo estableciendo como fecha inicial 30 de junio de 1991, donde la desgravación seria 46\% hasta llegar al 31 de diciembre de 1994 con un $100 \%$ de desgravación, disponiendo un año de gracia Paraguay y Uruguay, estableciéndose por supuesto un régimen general de origen, solución de controversias y cláusulas de salvaguarda.

Además, se ha negociado la instrumentación de un Arancel Externo Común, la Coordinación de Políticas Macroeconómicas y Sectoriales, Agrícola, Industrial, Monetaria, Financiera, Aduanera de Comercio Exterior y de Transporte y Comunicaciones, se ha establecido además la armonización de las legislaciones respectivas. 
La CEPAL ha señalado que a principios de 1994 se había cumplido alrededor del $75 \%$ de los compromisos asumidos (Castro, 1994: 993).

Se ha establecido como fin la negociación para la creación del mercado común entre los cuatro países, con libre circulación de factores productivos.

Según lo discutido, la comparación entre lo viejo y lo nuevo de la integración, incluye una diferencia entre los instrumentos de política utilizados, en la actualidad el factor fundamental es la liberación comercial donde se negocian listas de excepción y el resto de mecanismos se manejan como complementación, tal es el caso por ejemplo de la armonización de políticas públicas y la legislación con to cual se busca crear un marco propicio para que la libre competencia provocada por la desaparición de obstáculos arancelarios no tengan efectos distorcionantes. En anteriores acuerdos, la liberación entre países se acompañaba de la búsqueda de la industrialización y metas complejas de desarrollo integral, tal es el caso de los programas de desarrollo tecnológico o integración física. Estos últimos no constitulan fines complementarios, sino parte fundamental de los objetivos de la integración.

\section{Los logros de la integración}

Así como la década de los años 80 fue llamada "la década pérdida" para la América Latina, en lo económico y lo social; en cuanto a integración también se pudo observar un estancamiento importante a nivel de los acuerdos que hasta ese momento se habian firmado.
Sin embargo, la década de los 90 ha renovado el interés por los procesos integracionistas. Por ejemplo, solo entre 1990 y 1993 se suscribieron según datos de la CEPAL, por lo menos 120 acuerdos bilaterales, además de acuerdos como el MERCOSUR, grupo de los 3 y el Tratado de Libre Comercio de América del Norte.

Como se ha visto, se puede hacer explícito que la integración en el subcontinente latinoamericano ha entrado en una nueva etapa, en la cual el contexto ha estado caracterizado por programas de ajuste asumidos como modelos económicos, el paso de gobiernos militares a gobiernos democráticos; así como las exigencias de una economía mundial donde los altos niveles de competencia pero también de proteccionismo son elementos fundamentales, lo que ha determinado la pérdida de importancia relativa de las exportaciones latinoamericanas en el resto del mundo.

En este ambiente, el Pacto Andino es el segundo acuerdo en importancia en la región a pesar de las contradictorias informaciones que sobre este esquema subregional se han expuesto. Asi por ejemplo mlentras Santiago Escobar Sepúlveda (1993: 70) afirma que el Pacto Andino ha declinado en una simple área de preferencias aduaneras y Francisco Rojas (1993: 67) plantea que en la práctica ha desaparecido; otros autores como es el caso de la CEPAL afirman que el comercio en la subregión andina ha crecido en un $42 \%$ entre 1994 y 1995 y el intercambio interregional ha pasado de $10 \%$ a $12 \%$ en los mismos años (CEPAL, 1995: 36). 
Además existen datos que afirman que el Arancel Externo Común ya está en funcionamiento dentro del área Andina configurando de esta manera la Unión Aduanera. Este Arancel está distribuido según el nivel de elaboración de los productos, de tal manera que los insumos y las materias primas pagan solo $5 \%$, los productos semielaborados 10 y $15 \%$ y los bienes de consumo final abonan el $20 \%$ del arancel.

Cabe acotar que Bolivia tiene autorización para utilizar un Arancel Externo de $5 \%$ y $10 \%$, y a Ecuador se le ha permitido mantener una diferencia de 5 puntos con respecto al mismo sobre un universo mayor de 990 subpartidas.

Las listas de excepciones están conformadas por 400 subpartidas para Ecuador, 230 subpartidas para Colombia y Venezuela, siendo estas de carácter temporal (cuatro años máximo). Un número reducido de productos relacionados con la salud, la educación y la comunicación masiva contará con un Arancel Externo común de $0 \%$.

En cuanto a las relaciones de los miembros del Pacto Andino con el resto del Mundo, es importante mencionar que Venezuela y Colombia (Los mayores soclos) han actuado de manera independiente en Acuerdos de integración con México en el Grupo de los 3, así como en Acuerdos de cooperación con Centroamérica y la Comunidad del Caribe. Asimismo estos países junto a Bolivia buscaron realizar a mediados de los noventa conversaciones con el MERCO. SUR. Este tipo de iniciativas alejaban la posibilidad de negociar como bloque frente al resto del mundo.
Sin embargo, esto parece haber cambiado recientemente, y durante el mes de octubre de 1996, se han iniciado conversaciones entre la Comunidad Andina y el MERCOSUR.

En cuanto a MERCOSUR, se considera el mayor Acuerdo de integración entre los cuatro grandes esquemas integracionistas de América Latina y el Caribe.

El Comercio en el interior de la agrupación ha pasado de $19 \%$ en 1994 a $22 \%$ en 1995 . El Comercio se concentra en más de $60 \%$ entre Argentina y Brasil, principales socios comerciales. (CEPAL, 1995: 35).

En relación al Arancel Externo común del MERCOSUR, está en vigencia al igual que en el Pacto Andino a partir de 1995 para el $85 \%$ del Universo Arancelario con un promedio de $14 \%$ y un máximo de 20\%; cada uno de los países ha establecido aranceles distintos que varian entre 0 y $35 \%$ para el restante $15 \%$ del Universo Arancelario. Las excepciones incluyen los bienes de capital, informática y de telecomunicaciones. Los de capital deberán llegar a un Arancel Externo de $14 \%$ el $1^{\circ}$ de enero del año 2001 y los informáticos y de telecomunicaciones a un $16 \%$ el $1^{\circ}$ de enero del año 2006. (Ferrer, 1995: 819-820). Asimismo las listas de exenciones abarcan 300 productos en el caso de Argentina, Brasil y Uruguay, y 339 artículos para Paraguay, estas listas al igual que en el Grupo Andino son temporales y quedarán sin efecto a partir del año 2001.

En referencia a las relaciones con el resto del Mundo MERCOSUR se ha acercado en bloque, a diferencia de los 
miembros del Grupo Andino, fundamentalmente a Chile, pero el principal acuerdo ha sido firmado en 1995 con la Unión Europea, este acuerdo tiene como fin la cooperación comercial y

económica entre ambos tratados. Este constituye el primer documento diplomático del género firmado por dos sistemas regionales de integración. Este Acuerdo tiene como objetivo principal desarrollar la cooperación económica, asi como estimular el diálogo político institucionalizado entre los dos grupos de países. (Tachinardi, 1995: 1).

\section{Conclusiones}

El nuevo impulso a los procesos de integración Latinoamericana ha sido una caracteristica importante de las economías de la región en la última década. Este proceso se ha producido en el marco de la apertura comercial, a diferencia de la integración de los años 60 en donde la sustitución de importaciones constituía el modelo de desarrollo de los países.

Esto ha condicionado los estilos de la integración en cuanto a los mecanismos utilizados, la configuración institucional del proceso y los objetivos asignados a los acuerdos integracionistas.

De esta manera podría apreciarse lo viejo de la integración en el antiguo Acuerdo de Cartagena en el cual la protección, la programación industrial, los complejos objetivos del proceso así como las grandes y diversas instituciones creadas; se diferencian de lo nuevo de la integración cuyos paradigmas, el MERCosur y el Actual Grupo Andino, se caracterizan por buscar la inserción en la economía mundial, la apertura comercial acelerada y para esto el mecanismo prevaleciente es la concertación directa entre Presidente, Ministros, grupos económicos y técnicos.

El principal desafío de esta nueva integración es evaluar hasta qué punto en un mundo donde el libre comercio sigue siendo una utopía, a la luz del creciente proteccionismo de los paises industrializados y la competencia desleal, es factible llevar a cabo la integración bajo el esquema de apertura indiscriminada y unilateral. Es importante también considerar la viabilidad de seguir con un patrón de integración donde se privilegian los aspectos comerciales y se abandonan o se consideran a medias metas de índole política, social y cultural, que vale recordar no han dado resultados mayores y menores en modelos anteriores de integración, en gran parte por falta de voluntad, política.

La nueva gerencia de la integración tendría que visualizar que la misma es un proceso multidinámico en el cual se procede a planificar, organizar, dirigir y controlar el intercambio no solo de bienes, servicios y mano de obra sino también las necesidades sociales y la cultura de los paises signatarios.

Empero, el gigantismo institucional creado con el fin de dar respuesta a las metas de la integración en el marco de la búsqueda del Desarrollo no ha sido la vía más efectiva. El equilibrio parecería estar en una verdadera armonización de las decisiones políticas de los países miembros de los acuerdos y la coordinación así como la acción conjunta de sus estrategias de desarrollo; asimismo el ejercicio 
de una verdadera voluntad politica en la cual la integración aparezca como medio, parte y fruto del desarrollo social y en la que tanto los estados gobiernos como las Instituciones que sean creadas y los sectores privados de los países signatarios asuman posiciones adaptadas a los múltiples requerimientos de las sociedades Latinoamericanas, entre los cuales la inserción en los mercados mundiales aparece como parte y no como el único horizonte al cual se debe conducir esta región.

\section{Referencias Bibliográficas}

Agosin, Manuel y French-Davis, Ricardo, (1994), La Liberación Comercial en América Latina, Revista Nueva Sociedad, Ne 133, pp 54-71, Editorial Texto, Caracas - Venezuela

Baumann, Renato, (1993), Integración y Desviación del Comercio, Revista de la CEPAL, N 51, pp 133-148, Comisión Económica para la América Latina, Naciones Unidas, Santiago de Chile.

Bouzas, Roberto (1993), Apertura Comerciale Integración en el Cono Sur, Revista Nueva Sociedad, № 125, pp 112-119, Editorial Texto, Caracas - Venezuela.

Castro, Alfredo, (1994). EI MERCOSUR Contra Viento y Marea, Revista Comercio Exterior, Vol $44 N^{\circ} 11$, pp 990-1000, Banco Nacional de Comercio Exterior, México DF. - México.

Centro Interuniversitario de Desarrollo (CINDA), Instituto de Altos Estudios de América Latina de la Universidad Simon Bolivar (IALALC). (1987), Manual de Integración Latinoamericana, Centro Interuniversitario de Desarrollo (CINDA), Caracas.

Comisión Económica para la América Latina (CEPAL), (1995), Balance Preliminar de la Economía de América Latina y el Caribe 1995; Notas sobre Economía y Desarrollo, $N^{2}$ 585/586, pp 35-45, Naciones Unidas, Santiago de Chile.

Escobar, Santiago, (1993), La Polltica de la Integración, Revista Nueva Sociedad, NN 126, pp 62-71, Editorial Texto, $\mathrm{Ca}$ racas - Venezuela.

Ferrer, Aldo, (1995), MERCOSUR: Trayectoria, situación actual y perspectivas, Revista Comercio Exterior, Vol. 45, Ne 11, pp 819-831, Banco Nacional de Comercio Exterior, México D.F.

Fuentes, Juan (19940, El Regionalismo Abierto y la Integración Económica, Revista de la CEPAL, № 53, pp 81-89, Comisión Económica para la América Latina, Naciones Unidad, Santiago de Chile.

Morón de Macador, Beky, (1994), el Comercio Internacional y la propuesta reoconservadora de MERCOSUR, Revista Nueva Sociedad, No. 133, pp. 102 117, Editorial Texto, Caracas - Venezuela.

Ramos, Joseph (1993), Crecimiento, Crisis y Viraje Estratégico, Revista de la CEPAL, N2 50, pp 63-79, Comisión Económica para la América Latina, Naciones Unidad, Santiago de Chile.

Rodríguez, Jorge (1992), Reflexiones sobre la integración Andina en un contexto de Apertura Económica, Revista Integración Latínoamericana, N⿳2 176, pp 3 12. Instituto para la Integración de América Latina, Buenos Aires - Argentina.

Plojas Aravena, Francisco (1993), América Latina, el dificil camino de la Concertación y la Integración, Revista Nueva Sociedad, N2 125, pp 60-69, Editorial Texto. Caracas - Venezuela.

Rojas, Osvaldo, (1988), Balance y Renovación del Paradigma Estructuralista del Desarrollo Latinoamericano, Revista de la CEPAL, N²34, pp 19-36, Comisión 
Económica para la América Latina, naciones Unidad, Santiago de Chile.

Fosenthal, Gert, (1993), la Integración regional en los años noventa, Revista de la CEPAL, N* 50, pp 1.19, Comisión Económica para la América Latina, Naciones Unidad, Santiago de Chile.

Salgado, Germánico, (1993), Integración Andina y Apertura Externa, Revista Nueva Sociedad, № 125, pp 130-131, Editorial Texto, Caracas - Venezuela.

Schuarzer, Jorge (1993). El MERCOSUR, la Geografía a la espera de Actores, Re- vistas Nueva Sociedad, № 126, pp 72-83, Editorial Texto, Caracas - Venezuela.

Tachinardi, María (1995), Unión Europea "Corona" el bloque MERCOSUR - suplemento de Gaceta Mercantil, № 21, pp 1-10, Red de Diarios Económicos. San Paulo, Brasil.

Thoumi, Francisco (1993), Estrategias de Desarrollo, Convergencia de Políticas e Integración Económica, Revista Nueva Sociedad, № 125, pp 70-77, Editorial Texto Caracas - Venezuela. 